Ruzigul Umarova

$\mathrm{PhD}$, Docent

The Tashkent Automobile and Road Institute umarova-70@inbox.ru

\author{
p-ISSN: 2308-4944 (print) e-ISSN: 2409-0085 (online) \\ Year: $2015 \quad$ Issue: $10 \quad$ Volume: 30 \\ Published: $30.10 .2015 \quad$ http://T-Science.org
}

SECTION 30. Philosophy.

\title{
SOME ASPECTS OF THE RELATIONS OF NATURE, MAN AND SOCIETY IN THE VIEWS OF ABU ALI IBN SINA AND ABU RAYHAN BERUNI
}

Abstract: This article conducted a small comparative analysis of the views of Abu Ali Ibn Sina and Abu Rayhan Beruni about interactions in the system "Nature-Man-Society".

Key words: personality, nature, society, life force, mental activity, noosphere, geographic determinism, environmentalism.

Language: Russian

Citation: Umarova R (2015) SOME ASPECTS OF THE RELATIONS OF NATURE, MAN AND SOCIETY IN THE VIEWS OF ABU ALI IBN SINA AND ABU RAYHAN BERUNI. ISJ Theoretical \& Applied Science 10 (30): 127-129.

Soi: http://s-o-i.org/1.1/TAS-10-30-27 Doi: crossef http://dx.doi.org/10.15863/TAS.2015.10.30.27

\section{НЕКОТОРЫЕ АСПЕКТЫ ВЗАИМООТНОШЕНИЙ ПРИРОДЫ, ЧЕЛОВЕКА И ОБЩЕСТВА ВО ВЗГЛЯДАХ АБУ АЛИ ИБН СИНО И АБУ РАЙХАН БЕРУНИ}

Аннотация: В данной статье проводится небольшой сравнительный анализ воззрений Абу Али Ибн Сино и Абу Райхан Беруни относительно взаимоотношений в системе «Природа-Человек-Общество».

Ключевые слова: личность, природа, общество, жизненная сила, умственная деятельность, ноосфера, географический детерминизм, инвайронментализм.

Интерес к наследию одного из величайших мыслителей человечества Абу Али Ибн Сины с каждым годом неуклонно возрастает. И, казалось бы, ничего нет нового под Луной, однако, в произведениях Ибн Сины, с каждым новым прочтением и новым переводом, научный мир открывает для себя целый океан неизвестных и непонятных вещей, сил природы, феноменов мира идей, очередных загадок мира души. Душа во все времена считалась неким таинством, неподвластным пониманию простого смертного. За завесу этой тайны попытались заглянуть сначала древние философы, а затем теоретическую основу учения о душе заложил Аристотель, а на Востоке вслед за «Первым учителем» «Второй учитель» во многом способствовал продолжению этого учения. В трудах «Авторитета Истины», как часто именовали Ибн Сину, можно найти обоснование и дальнейшее углублённое изучение и анализ мира души.
С точки зрения постепенности перехода от воспринимающих сил животного к умственной деятельности человека чрезвычайный интерес представляет эстимативная (оценивающая) сила, выделение которой в особую способность животной души характерно именно для Ибн Сины. Эстимативная сила схватывает в единичных предметах идею, то есть нечто подобное гештальту (образу-отпечатку) или общему представлению.

Способность животных иметь идеи, общие представления (например, чувства материнства к своему детёнышу и чувство враждебности к врагу, хищнику) определяет, по Ибн Сине, и другую их способность, сближающую животное царство с миром людей, - способность к созданию «искусственных вещей» (птицы вьют гнёзда, муравьи и термиты создают свои «дворцы»). Однако, согласно Духовному Наставнику, эти искусства больше сопряжены с инстинктивной деятельностью. Впрочем, у человека это тоже проявляется, когда он строит 
дома, сооружения, защищая себя от сил природы. Однако сила эта в мире людей идёт дальше и глубже. Человек способен творить и искусственный духовный мир. Если духовный мир человека, несомненно существует, то касательно духовного мира животных однозначно отрицательного ответа не существует. Более того, сегодня можно сказать с уверенностью, что у некоторых животных (кошек, собак, птиц) проявляется, например, определённая тяга к музыке, особенно классической. Причём тяга эта формируется не в результате дрессировки, а является врождённой. Данный аспект на сегодняшний день является очень актуальным, так как согласно представителям инвайронментализма (современного учения о взаимодействии человека со средой обитания) нельзя однозначно наделять ощущением духовного мира только человека.

Психические силы венчает свойственная человеку разумная душа, которая определяется как первое завершение естественного органического тела в той мере, в какой оно совершает действия благодаря осмысленному выбору и рассуждению и поскольку воспринимает общее. Но разум не только опирается на силы, которые «служат» ему, он очеловечивает, сублимирует (переносит) их. А те со своей стороны стремятся «дегуманизировать» человека, низвести его до животного уровня.

Особенно интересны рассуждения Ибн Сины о двойственной и противоречивой роли воображения. Разуму не обойтись без него постольку, поскольку оно «служит тебе соглядатаем и дозорным: через него доходя до тебя сведения о том, чего не видно с твоей стороны и что удалено от местоположения твоего» [1]. Но в то же время эстимативная и имагнитивная (восприятие изящного и прекрасного) силы могут подменить силу разума и в таком случает это может привести к тому, что эти силы дают ложное представление человеку о достижении счастья без посредничества разумной силы.

Разум венчает иерархию психических сил, но в то же время он и сам имеет определённым образом иерархизированную структуру, компоненты которой связаны между собой точно таким же отношением «главенствования и служения». Прежде всего, разумная душа делится на практическую и теоретическую силу. «Практическая сила является началом движения человеческого тела, побуждающим его совершать единичные, осмысленные, соответствующие тем или иным намерениям действия» [2].

Практический разум отличается от теоретического так же, как должное, запретное и разрешённое от необходимого, невозможного и возможного первые представляют невысказывающие речения, вторые высказывающие. Другими словами, практическая сила души вырабатывает нравственные принципы, не имеющие касательства к истине и лжи, а теоретическая - знания, направленные на то, чтобы постигать истину и избегать лжи. В этом и видится отличие учения Ибн Сины о познавательной способности души от учения о «двойственной истине» Ибн Рушда.

Теоретическая сила отличается от прочих сил тем, что может оперировать общими формами, абстрагированными от материи. Эти формы бывают или сами по себе отвлеченными, или сохраняющими связи с материей. В первом случае они будут просто приниматься теоретической силой, а во втором абстрагироваться ею от указанных связей.

Подводя итог достаточно короткому анализу одного из аспектов учения о душе Ибн Сины, можно сказать, что на современном этапе развития мира, к сожалению констатируется факт того, что по сути дела человек не научился контролировать свои инстинкты и порой эстимативная сила возвышается над разумной. Многому можно научиться у природы и потому правильные взаимоотношения человека и окружающей среды позволят с оптимизмом взглянуть на будущее.

Человек неотделим от окружающей среды. Однако природа существовала задолго до человека и, следовательно, способна существовать и без него. Точки соприкосновения человеческого существа и окружающего мира вызывали неподдельный интерес у философов древних веков, и этот же интерес является естественным в XXI веке. О влиянии географической среды на человека, его характер, нрав, поведение и даже политику в европейской традиции говорил Шарль Луи Монтескьё. Но заложил основы географического детерминизма один из величайших учёных-энциклопедистов Востока Абу Райхан Беруни. Конечно, до Беруни такого рода догадки высказывали и Платон и Аристотель, но достаточного обоснования фактов влияния среды на человека в частности и общества в целом они не оставили. В последней четверти XX века широкое распространение получили различного рода концепции инвайронментализма. Инвайронментализм как учение об окружающей среде, человеко-средовых отношениях, средология или энвироника своими корнями уходит в американскую социальнофилософскую и социологическую мысль, а также восходит к русскому космизму. По Беруни, природная среда оказывает решающее влияние на развитие целых народов, их нрав, характер и способность ведения сельского хозяйства, а также политических дел. Но в то же самое время среда представляет для человека угрозу, перед

ISPC Innovations in science, 
лицом которой в одиночку справиться невозможно. Поэтому среда, окружающая индивида включает в себя ещё и других индивидов, которые, действуя сообща, создают мир второй природы и противостоят врагу в лице других людей. Таким образом, можно выделить два типа окружающей среды относительно индивида: агрессивная среда и плодотворная среда. Беруни делает вывод: «Человек же из-за своей наготы и немощности, из-за отсутствия органов [защиты], подвергаясь испытаниям со стороны других, чувствует постоянную необходимость в том, что его защищало бы, и потребность в том, что удовлетворяло бы его нужды» [3].

Сегодня налицо факт грубого вмешательства человека в окружающую среду. Если Беруни пишет о рациональном использовании среды человеком для своего блага и предлагает пользоваться только тем, что особенно необходимо для удовлетворения основных потребностей, то современное развитие индустрии, военной промышленности и всех видов техники показывает гипертрофированное нерациональное использование средовых ресурсов, которое может привести к уничтожению живой среды и элиминации неживой природы непосредственно окружающей человека. Современные представители инвайронментализма, такие как А.Леопольд,
Р.Данлэп, Р.Паэлке, У.Кэттон, Л.Ф.Шноре, О.Данкан, О.Н.Яницкий и др. предлагают вывести человеко-средовые отношения на совершенно новый уровень и заменить парадигму человеческой исключительности новой инвайронментальной парадигмой. Можно сказать, что установление новой парадигмы станет важным шагом на пути к формированию ноосферы. Именно о силе разума совместно с деятельностью сообразной географической среде и говорил Беруни. Однако идеи Беруни не зашли так далеко вследствие отсутствия глобальных проблем в его время. В наши дни мы столкнулись с опасностью отторжения человека окружающей средой как лишнего элемента. Речь может идти о невозможности существования на нашей планете уже в недалёком будущем, если человекосредовые отношения будут решаться только в пользу первого. Инвайронменталисты выдвигают природную среду на ноосферный уровень. Это, однако, пока могут принять не все. Опираясь на исторический опыт, в частности на идеи Беруни о взаимодействии человека и среды, используя современные технологии в преподавании, необходимо больше внимания уделять инвайронментальной педагогике, так как именно рациональное человеко-средовое воспитание поможет сформировать подлинно гуманистическое мышление и отношение не только к человеку, но и к природе.

\section{References:}

1. Ibn Sina (1980) Traktat o Khayye, syne Yakzana . Per . A.V.Sagadeyeva . - Sagadeyev A.V. Ibn Sina ( Avitsenna). Moscow, 1980. pp. 120-121.

2. Sagadeyev AV (1985) Ibn Sina. Moscow, Mysl' , 1985. pp. 122.

3. Abu Raykhan Beruni (1998) Mineralogiya ... pp.273 // Osnovy filosofii . T. , 1998 pp.96

4. Ibn Sina (1980) Izbrannyye filosofskiye proizvedeniya. - Moscow: Nauka, 1980.

5. Al'-Biruni, Ibn Sina (1973) Perepiska. Tash $\neg$ kent: Fan, 1973.

6. Frolova EA, Ibn Sina (2000) Novaya filosofskaya entsiklopediya: v 4 t. / In-t filosofii
RAN; Nats. obshchestv.-nauch. fond; Preds. nauchno-red. soveta V. S. Stopin. - Moscow: «Mysl'», 2000-2001.

7. Shidfar BY (1981) Ibn Sina-. - Moscow: «Nauka», 1981. - 184 p.

8. Timofeyev IV (1986) Biruni. - Moscow: Molodaya gvardiya, 1986. - $304 \mathrm{p}$.

9. Sharipov A (1972) Velikiy myslitel' Abu Raykhan Biruni. Tashkent, Fan, 1972.

10. Rozenfel'd BA, Rozhanskaya MM, Sokolovskaya ZK (1973) Abu-r-Raykhan AlBiruni, 973-1048. Moscow: Nauka. 1973. 